\title{
Intersectionality Research in Psychological Science: Resisting the Tendency to Disconnect,
}

\section{Dilute, and Depoliticize}

NiCole T. Buchanan \& Lauren O. Wiklund

Michigan State University

Department of Psychology

East Lansing, MI, US

This is a post-peer-review, pre-copyedit version of an article accepted for publication in Research on Child and Adolescent Psychopathology on 11/30/2020. The final authenticated version is available online at: http://dx.doi.org/10.1007/s10802-020-00748-y

\section{Author Note}

NiCole T. Buchanan (iD https://orcid.org/0000-0001-9288-5245

Lauren O. Wiklund (D) https://orcid.org/0000-0001-9997-0813

Correspondence concerning this article should be addressed to NiCole T. Buchanan, Department of Psychology, Michigan State University, 316 Physics Rd, East Lansing, MI, 48824. E-mail:nbuchana@msu.edu. 


\begin{abstract}
Psychological science has been slow to incorporate intersectionality as a concept and as a framework for conducting research. This limits not only the potential for intersectionality theory, but also limits the potential impact of the research claiming to use it. Mennies and colleagues conducted a study of psychopathology and treatment utilization using a large racially diverse sample of youth and frame their work as intersectional because they compare across three social categories (race, sex, and social class) and consider social issues that may impact the groups studied. We argue that while this represents a preliminary step, it does not represent intersectionality theory and praxis. In this article we review intersectional theory and praxis, examine psychological science and its resistance to fully incorporating intersectionality, and highlight how research must shift to be truly intersectional. Finally, we issue a call to the field to integrate intersectionality theory and praxis and to resist the tendency to dilute and depoliticize intersectionality theory and disconnect from its social justice frame.
\end{abstract}

Keywords: Intersectionality, Social justice, Psychological science, Research methods, Multiculturalism, Social group membership 


\section{Intersectionality Research in Psychological Science: Resisting the Tendency to Disconnect, Dilute, and Depoliticize}

Psychological science has been slow to incorporate intersectionality as a concept and as a framework for conducting research (Settles et al., 2020; Warner et al., 2016). Although there has been an increase in the use of the term, it is rarely centered in mainstream psychology publications, is not taught as a research framework, and is commonly misunderstood and undervalued (Cole, 2009; Rosenthal, 2016). As both a theory and an analytic framework, intersectionality has been subject to epistemic exclusion, rendering it largely invisible in psychology and cast to the margins of the field (Settles et al., 2020). When intersectionality is brought into mainstream psychological research, it is depoliticized, disconnected from its social justice frame, and diluted (Alexander-Floyd, 2012; Collins, 2017), typically incorporating more than one social identity (e.g., race and gender) analytically, but failing to utilize the other core components of intersectionality (see Table 1). As a consequence, psychological research and the field as a whole, have not benefited from the transformative potential that emerges from intersectional praxis (Collins \& Bilge, 2016; McCormick-Huhn et al., 2019).

Mennies and colleagues (2020) conducted a study of youth psychopathology and treatment utilization from the Adolescent Brain and Cognitive Development (ABCD) study. Their work goes a step further than research that merely examines two or more identities by providing a critique of the social structures and barriers that contribute to health inequities among youth. In this commentary, we identify the strengths of their study while arguing that it does not qualify as intersectional research and offer suggestions for the authors and the broader field of psychology on how to conduct research that embodies the core tenets of intersectionality praxis. 


\section{Intersectionality: A Primer}

Intersectionality as a conceptual framework has been central in Black feminist activism and scholarship for nearly two hundred years. Sojourner Truth delivered her "Ain't I a Woman" speech at the 1851 Women's Rights Convention where she called out the hypocrisy of abolitionists and White suffragettes, which centered either White women or Black enslaved men and rendered the unique oppression experienced by Black women invisible and undefended. For nearly two centuries, women of color activists and eventually women of color, lesbian and transgender scholars have been vocal about oppression at the intersections of classism, racism, heterosexism, ableism, and xenophobia (see Buchanan et al., 2020). In 1989, Black feminist legal scholar, Kimberlé Crenshaw presented a framework for intersectionality theory, naming the construct and unifying a long history of scholarship and activism.

At this point in psychology, many understand intersectionality as a focus on overlapping identities, such as being both Black and female, yet dismiss the other core tenets of intersectionality theory (Table 1), particularly its central focus on social justice (Cole, 2009; Collins, 2000; Collins \& Bilge, 2016; Crenshaw, 1989; Settles \& Buchanan, 2014). A critical contribution of intersectionality theory is that it centers understanding how a given phenomenon is inextricably intertwined with societal and institutional structures and interlocking systems of privilege and oppression. As such, work that is based in intersectionality theory intentionally focus on the "forces that create the outcomes, not just their static products" (MacKinnon, 2013, p. 1023). For example, an intersectional analysis would center institutionalized discrimination in medical training and racist and sexist biases of providers as the dynamic factors impacting the disparate health outcomes between Black and White women in the U.S. (Baker et al., 2010). Rather than simply reporting racial differences in pregnancy related deaths, intersectional 
research exposes systemic racism and sexism as the mechanism driving these differences. Moreover, intersectionality theory is not limited to research on individuals that hold multiple stigmatized identities. Intersectionality theory can, and should, also be applied to analyses of power and oppression among groups that experience compounded advantage, such as White men, and how their positionality may be complicated if they have hidden stigmatized identities (e.g., low income origins; Kallschmidt \& Eaton, 2019).

As intersectionality moves into the center of psychological research, it is being depoliticized, disconnected from its social justice frame, and diluted (Alexander-Floyd, 2012; Bilge, 2013; Collins, 2017). What remains is focused on two or more identities without analyzing systems of power that undergird inequality and oppression and without agitating for systemic change. While this is more palatable to broad audiences, it is not intersectional research. Intersectionality without a central focus on structures of power and oppression and sans social justice foci undermines intersectionality's potential, stymies intersectional research in the field, and enervates its power to radically transform society.

As mainstream psychology flattens intersectionality theory to only a discussion of overlapping identities, it is also being confused with related, but distinct concepts, such as minority stress and multiple jeopardy. Minority Stress Theory (Brooks, 1981; Meyer, 2003) suggests that minoritized people are at an increased risk for mental health concerns due to the additional stress of prejudice and stigma. This concept was created to explain the disparate prevalence of mental disorders found among lesbian, gay, and bisexual individuals compared to heterosexual individuals. Minority Stress theory seeks to understand the potential negative mental health effects of experiencing discrimination and internalized stigma but does not explain how multiple minoritized identities interact and uniquely impact an individual's experience. This 
is in stark contrast to intersectionality theory's second core tenet that states we cannot understand the subjective experience of one social group membership without understanding the others. Additionally, while prejudice and stigma allude to larger societal structures that create and uphold identity-based biases, systemic oppression is not central to the theory and there is no call to action for dismantling systems of power and oppression.

Multiple jeopardy theory (Beale, 1970; Bowleg et al., 2003; King, 1988) posits that each stigmatized identity one holds can be targeted for mistreatment and therefore, each of these identities compounds our risk for mistreatment. As a result, membership in multiple marginalized identity groups significantly increases one's risk for victimization, accumulated disadvantage, and subsequent psychological, physical, and occupational harm. Multiple jeopardy is a contrast to multiple advantages accrued by those with multiple privileged identities. Importantly, multiple jeopardy differs from intersectionality in that it specifically addresses the multiplicative risk of harm because marginalized identities are targeted for victimization. Importantly, multiple jeopardy is a framework for understanding increased risk among multiply marginalized people, but it is not beholden to the core tenets of intersectionality theory described in Table 1 and does not mandate social justice praxis.

We assert that empirical research in mainstream psychology that claims it is intersectional is actually using multiple jeopardy and minority stress frameworks and falls short of fully meeting the requirements of intersectionality theory. The misrepresentation and diluting of intersectionality theory both reflects and reifies biases regarding intersectionality theory and intersectionality scholars. Isis Settles and colleagues (2020) argue that psychology has resisted intersectionality theory and that by subjecting it to epistemic exclusion (Dotson, 2014), the field tightly restricts its (in)visibility (Buchanan \& Settles, 2019) such that it is largely invisible in 
psychology and when visible, reflects only a diluted and distorted form. As such, scholars relying on literature in psychological science to build their own intersectional research replicate research that, at best, uses a multiple jeopardy framework. Over time, the true definitions of intersectionality theory are lost and disciplinary memory of its definition is limited.

\section{Intersectionality: Application and Praxis}

Elizabeth Cole (2009) presented three questions that can be applied to each stage of research to ensure that intersectionality is being addressed appropriately: 1) who is included within a social category, 2) what role does inequality play, and 3) what are the similarities across categories that are often perceived as different? Questioning who is within a study sample goes beyond just including groups that have been ignored in psychological research and pushes for an examination of the diversity within demographic categories. For example, an examination of Black families should include families of different socio-economic levels, with different abilities, and a variety of parent structures. Presenting findings as they relate to Black families within a particular sample in this case would be incomplete and while no one study can include all of the variability of a demographic group, identifying the possible variability and then appropriately describing who is and is not represented in a study provides an appropriate lens for comparison. Truly applying intersectionality theory to who is included in a study has the power to dismantle stereotypical beliefs of singular demographic categories by showcasing how social location shapes the significance of that category.

The second question implores researchers to identify the role of historical and contemporary structural inequality that impinge upon group members. Using the same example of Black families, researchers must consider the positionality of the various groups represented in, and omitted from, the study sample. Considering how historical structural inequality, such as 
redlining ${ }^{1}$, is connected to contemporary structural inequality, such as the under-resourcing of local schools, changes the types of support families may have for academic remediation and enrichment. Black families whose children attend under resourced schools may engage in parenting practices that differ from families in high resourced schools because structural inequality created unequal opportunities for their children that, in turn, impact parenting options. Examining the role of inequality requires making the connection between membership with a given demographic category and how these structural positions are related to unequal access to power and resources.

Finally, Cole (2009) asserts that intersectional research moves beyond a focus on group differences to also ask about, potentially hidden, similarities across groups. Asking this question can lead to a recognition of shared needs, values and goals that create the potential for coalitionbuilding and reducing barriers to connection. One example could be examining Black families and considering where there are similarities to Latinx families. In discovering both parents groups engage in racial socialization to protect their children from police brutality, researchers and participants might work together for changes in the institutional practices of policing that create different, but similar, harm for both communities. Such efforts build connections across groups, while embracing the nuance within groups, and strengthens both groups by increasing coalitions to end oppressive systems that affect them both.

Using both Cole's and Rosenthal's frameworks can illuminate strengths in the Mennies and colleagues' (2020) study, identify where it strayed from being intersectional, and provide suggestions for moving the work toward a truly intersectional lens. Mennies and colleagues’

\footnotetext{
${ }^{1}$ The term redlining refers to the color that banks and financial lenders coded predominantly Black neighborhoods as least desirable when conducting appraisals for community development. This institutionalized practice translated into denying Black individuals mortgage loans or only lending predatory and sub-par loans as a way of systemically segregating neighborhoods in relations to resources (Mendez, 2014).
} 
partially address Cole's first question regarding who is included in a social category, who has been centered or ignored in research, and what variability exists within the groups. Their work expands traditional research by "focusing on groups that have been neglected" (Cole, 2009, p. 172) by using a nationally representative dataset that included diverse families (racial minorities, lower SES) that are usually neglected in pediatric psychological studies. Their Venn diagram nicely depicts the overlapping categories of privileged and marginalized identities participants in their study might embody. Their introduction and discussion highlights Cole's second question regarding the role of inequality by discussing how systemic racism, discrimination, exposure to trauma, access to mental health services, and experiencing multiple forms of oppression contributes to race and gender disparities mental health that are compounded among those with multiple marginalized identities. These factors make it an example of quality research advancing the field by complicating questions around risk and vulnerability, but they are insufficient to argue that it is intersectional research.

A significant concern is their narrow conceptualization of intersectionality theory. The authors frame intersectionality as positing that overlapping systems of oppression put multiply marginalized people at increased risk and that significant interaction terms (e.g., sex, race, social class) support intersectionality's basic tenets. This definition of intersectionality fails to address power, oppression, or increasing understanding of the context that creates potential differences. This definition also implies that marginalized people are the only ones subject to intersectionality, when in fact those with multiple privileged identities are also central to intersectionality theory. Instead, the definition the authors rely on is more accurately depicting multiple jeopardy theory and mistaking it for intersectionality theory. Sadly, this is not uncommon in empirical research published in psychology. As intersectionality has increased in 
popularity, it has been diluted to include its most rudimentary components. Reviewing the works cited, there appears to be little drawn from the vast work robustly defining and centering intersectionality in its true form, nor work critical of psychology's (mis)use of intersectionality theory (examples include Grzanka et al., 2017; McCormick-Huhn et al., 2019; Settles et al., 2020; Warner et al., 2016). Without drawing on these bodies of work, which are rarely accepted in high impact psychology journals (Settles et al., 2020), and only focusing on mainstream psychology research that calls itself intersectional, the authors would only be exposed to the diluted or "flattened" version that they replicated (Alexander-Floyd, 2012). Being an intersectionality scholar requires reading outside our comfort zones and top tier mainstream psychology journals.

Intersectional research requires a focus on justice and examination of oppression, and is cognizant of the importance of the language used to describe these relationships. The authors miss the core of intersectionality when they use language such as, "oppression and adversity may also be perpetuated through the effects of identifying with multiple non-dominant identities." Identifying with marginalized identities does not perpetuate oppression. Systems and individuals with power create and perpetuate oppressive systems that disproportionately harm those with marginalized identities. Language needs to be shifted to acknowledge the structural inequities and their impact on identities first. For example, the interaction of racism, sexism, and poverty uniquely shape the experiences of youth and families that are marginalized within these systems and barred from accessing quality care and services. Similarly, the venn diagram identifies overlapping demographic categories. A focus on intersecting systems of oppression would relabel the categories of focus as racism, sexism, and classism to more accurately reflect how one's identities within these systems are impinged upon by oppression, barriers, and 
discrimination. These may appear to be small changes, but they reconstruct the meaning and understanding of how oppression occurs and who is responsible for the harm that ensues.

Intersectionality research is directly tied to systems of power and oppression and as such, it is not neutral or depoliticized. Mennies and colleagues fail to actively discuss critical contextual factors related to their findings. For example, "racism" appears twice in an introductory paragraph reviewing how systemic racism may contribute to racial trauma and reduced access to quality care. Privilege is mentioned once to say marginalized people experience "compounded marginalization by systems of privilege." True intersectional research has the transformational power to break theoretical research barriers and push social justice action. Privilege must be discussed within the sociopolitical framework in which it exists and use the political language of our reality to include discourse on power, privilege, and oppression.

Given its connection to systems of power and oppression, changes are needed to the study design, procedures and analysis to make the Mennies and colleagues study intersectional. Ideally, intersectional research would use measures that are developed from the perspective of the identified population and would include measures that examine larger systems of oppression and their manifestation. The authors appropriately identified that factors outside of the individual could influence group differences in mental health, such as systemic racism. Intersectional research strives to incorporate those factors to better understand the mechanisms underlying group differences, such as increased harassment and discrimination. Although some may be proxies for systemic oppression, other measures, such as the Life Events Scale, Perceived Discrimination Scale, Neighborhood Safety/Crime Survey and the School Risk \& Protective Factors Survey, were available in the data and could have been used to investigate how oppression influenced group differences. 
Rather than centering the role of oppression and inequity, Mennies and colleagues' hypotheses revert to a singular focus of differences by gender, race, SES and their categorical intersections. Moreover, despite their racially diverse sample, the authors missed the opportunity to attend to diversity within groups, despite intersectionality theory's assertion that categories (e.g., of race) do not fully explain one's subjective experience of their race because it is shaped by the other identities one holds. One surprising example was their handling of multiracial and Latinx participants. By counting anyone that identified as Hispanic without considering race, the authors reified notions of Latinx populations as homogenous and overlooks that within this category, people may also identify as, and be assumed to be, White, Black, Asian, or multiracial, with vast differences in experiences (e.g., discrimination) directly related to the study's hypotheses. Ideally, a robust assessment of Latinx children in the US would include both their ethnic and racial categorization as well as citizenship status of themselves and their parents, primary language use and proficiency, acculturation, and generational status in the US. Similarly, multiracial children were categorized in ways that may contribute to inaccurate classifications and the erasure of their experiences. First, the multiracial designation was based on answers to the race categories, not ethnicity. Any child that identified as Latinx was placed in the Latinx category, would not be included in the racial categories, and therefore, could not be considered in the multiracial designation. Further, the authors only included multiracial children that had at least one White parent. Children that were Black and Asian, Native American and Black, etc were not included in the study. Their handling of multiracial children is particularly troubling given findings that multiracial people often have the highest rates of past year and lifetime racial harassment, sexual harassment (Buchanan et al., 2009) and violent victimization (Warnken \& 
Lauritsen, 2019), with significant consequences for the mental health variables of interest in the Mennies study.

Multiracial children may have been handled this way analytically because the authors used a cutoff of 85 participants in each cell and the numbers of multiracial children with two parents of color did not meet this cutoff. This reflects another disconnect between the Mennies study and intersectionality theory and praxis. Power considerations often drive analytical decisions regarding whether or not to test for within group differences or whether to drop a group altogether. These tests are based on post-positivist assumptions that prioritize research being broadly generalizable rather than gaining deep understanding of a particular group's experience. Contrary to hegemonic research practices, generalizability is not a goal of intersectionality research. Truly intersectional work transcends mainstream requirements for statistical rigor and generalizability and asks instead that we illuminate inaccuracies in what is assumed to be universal or normative findings. With an intersectional framework, rather than dropping or inappropriately categorizing multiracial participants, one might find analytic strategies that would facilitate examining and deepening our understanding of their lived experiences.

To represent intersectional research, we also suggest Mennies and colleagues make several changes to the ways they report and discuss their research findings and future directions. For example, intersectional significance is not based on significant interaction effects. A 3-way interaction may be non-significant analytically, but there is still value in understanding the unique experiences and life perspectives resulting from the intersection of three identities related to race, gender, and social class. The non-significant interaction effects may instead reflect that we are using the wrong variables and methods, asking the wrong questions, or our reliance on strict quantitative analyses are too limited to illuminate uniquely meaningful relationships. 
In reporting findings, we must move beyond simply reporting group differences, even if we have compiled more nuanced groups in race, gender, SES combinations to identify why those differences exist and to name oppressive processes that perpetuate them. This might lead us to contextualize finding group differences in eating disorders, for example, by asking how we measure and define eating pathology, what is included, what is missing (e.g., food insecurity), and how any of these may change findings for the groups we are investigating. Similarly, there is little value in knowing that low income White families experienced increased service utilization, but low-income people of color did not. The more important findings relate to the assumptions we have about service utilization, income and race. Belief in meritocracy and that those with the greatest need are provided the most services is countered by these findings and points to systems of oppression that may fail to offer services or offer services that are not accessible or culturallyappropriate to low-income families of color. This focus shift also shifts our conceptualization of solutions and where to focus our queries, hopefully toward working with families to understand their needs and to collaborate with them on reenvisioning solutions.

Finally, to be intersectional, the research must include a call to action that promotes social justice. Mennies and colleagues state the need for validating screening measures and intervention methods of psychopathology in diverse groups, reducing barriers to treatment, and increasing diversity of care providers. All of these are astute and appropriate implications aimed at reducing the disparities highlighted within their study, but this does not go far enough. The third tenet of intersectional theory pushes beyond traditional boundaries of research as scholarly exercise and promotes real-life structural solutions based on study findings. Ideally this goes beyond the standard paragraph of vague implications and infuses the entire discussion of the results, and often the introduction, with ways that institutionalized injustices might be remedied. 


\section{Discussion}

It is exceedingly difficult to conduct research that fully embodies all of the tenets of intersectionality theory. No one study will address each aspect of intersectionality theory perfectly. Rosenthal (2016) uses Cole's questions to develop 5 strategies that can be taken as individual psychologists and as a field to make social justice an integral part of research, teaching, and clinical work. When considering who is included in the group being studied, Rosenthal (2016) suggests engaging the communities that are affected by the research in the processes that determine how research is done. Such collaborations should include not only the identified communities, but also those to whom the research might extrapolate. When asking about the role of inequality, Rosenthal (2016) suggests building coalitions as a powerful tool for highlighting connections between oppressed groups and addressing and changing societal structures of power and oppression. Additionally, she suggests increasing focus on acts of resistance, such as activism, as mechanisms for resilience and intervention. Studying resistance looks at the ways marginalized communities fight back rather than imagining them as agentic recipients of oppression. Finally, Rosenthal encourages social justice to be infused throughout every level of psychology training. Power, oppression, and social (in)justice could be standard topics across psychology curricula, which would naturally infuse intersectionality throughout training and research, however, as a field, mainstream psychology has resisted these topics (Buchanan \& Wiklund, 2020; McCormick-Huhn et al., 2019).

Scholars must work to better embody true intersectional theory and practice rather than allowing intersectionality theory flattening to continue unabated. The dilution of intersectionality theory perpetuates an inaccurate standard that further marginalizes the work of those utilizing intersectionality theory as intended (Buchanan, 2020; Settles et al., 2020). As more work is 
published using this term the dominant authority on what is and what is not legitimate intersectionality shifts. In a field where knowledge is constructed via peer review, published works have the power to either uphold or dismantle the application of theoretical frameworks. Disconnecting intersectionality theory from its social justice frame limits its very application and risks creating harm for the populations that researchers seek to study.

\section{Conclusion}

While acknowledging the difficulty in conducting intersectional research, embedded in our critique is a larger question of how far from these tenets can one stray before it is no longer intersectional research, and is merely a slightly more complicated comparison of groups. We assert that while no one study may achieve each benchmark, mainstream psychology has allowed too many papers to claim they are intersectional, without adhering to its basic tenets and often mislabeling multiple jeopardy theory or minority stress theory as intersectionality theory. This serves to dilute, depoliticize and disconnect intersectionality theory from its social justice frame, which may make it more palatable for mainstream psychology, but also limits its potential to radically transform the field.

Compliance with Ethical Standards: This paper does not contain any studies with human participants or animals performed by any of the authors."

Conflict of Interest: The authors declare that they have no conflict of interest. 


\section{References}

Alexander-Floyd, N. G. (2012). Disappearing acts: Reclaiming Intersectionality in the social sciences in a post-Black feminist era. Feminist Formations, 24, 1-25. https://doi.org/10.1353/ff.2012.0003

Baker, T. A., Buchanan, N. T., Spencer, T. (2010). Disparities and social inequities: Is the health of African American women still in peril? Ethnicity \& Disease, 20, 304-309. https://ethndis.org /priorarchives/ethn-20-03-304.pdf

Beal, F. M. (1970). Double Jeopardy: To Be Black and Female. Meridians: Feminism, Race, Transnationalism, 8(2), 166-176. https://doi.org/10.2979/MER.2008.8.2.166

Bilge, S. (2013). Intersectionality undone: Saving intersectionality from feminist intersectionality studies. Du Bois Review: Social Science Research on Race, 10, 405- 424. https://doi.org/10.1017/S1742058X13000283

Bowleg, L., Huang, J., Brooks, K., Black, A., \& Burkholder, G. (2003). Triple Jeopardy and Beyond: Multiple Minority Stress and Resilience Among Black Lesbians. Journal of Lesbian Studies, 7(4), 87-108. https://doi.org/10.1300/J155v07n04_06

Brooks, V. R. (1981). Minority stress and lesbian women. Lexington Books.

Buchanan, N. T. (2020). Researching while Black (and female). Women \& Therapy, 43(1/2), 91-

111. https://doi.org/10.1080/02703149.2019.1684681

Buchanan, N. T., Bergman, M. E., Bruce, T. A., Woods, K. C., \& Lichty, L. L. (2009). Unique and joint effects of sexual and racial harassment on college students' well-being. Basic and Applied Social Psychology, 31(3), 267-285.

https://doi.org/10.1080/01973530903058532 
Buchanan, N. T., Rios, D., \& Case, K. A. (2020). Intersectional cultural humility: Critical inquiry and praxis in psychology. Women \& Therapy, 34(3-4), 235-243. https://doi.org/10.1080/02703149.2020.1729469

Buchanan, N. T., \& Settles, I. H. (2019). Managing (in)visibility and hypervisibility in the workplace. Journal of Vocational Behavior, 113(2019), 1-5. https://doi.org/10.1016/j.jvb.2018.11.001

Buchanan, N. T. \& Wiklund, L. (2020). Why clinical science must change or die: Integrating intersectionality and social justice. Women \& Therapy, 34(3-4), 309-329. https://doi.org/10.1080/02703149.2020.1729470

Cole, E. R. (2009). Intersectionality and research in psychology. American Psychologist, 64, 170-180. https://doi.org/10.1037/a0014564

Collins, P. H. (2000). Black feminist thought: Knowledge, consciousness, and the politics of empowerment (2nd ed.). Routledge.

Collins, P. H. (2017). Intersectionality and epistemic injustice. In The Routledge Handbook of Epistemic Injustice (pp. 115-124). Routledge. https://doi.org/10.4324/978131521204311

Collins, P. H. \& Bilge, S. (2016). Intersectionality. Malden, MA : Polity Press

Crenshaw, K. (1989). Demarginalizing the intersection of race and sex: A Black feminist critique of antidiscrimination doctrine, feminist theory and antiracist politics. University of Chicago Legal Forum, 140, 139-167.

Dotson, K. (2014). Conceptualizing epistemic oppression. Social Epistemology, 28(2), 115-138. https://doi.org/10.1080/02691728.2013.782585 
Grzanka, P. R., Santos, C. E., \& Moradi, B. (2017). Intersectionality research in counseling psychology. Journal of Counseling Psychology, 64(5), 453-457. https://doi.org/10.1037/cou0000237

Kallschmidt, A. M., \& Eaton, A. A. (2019). Are lower social class origins stigmatized at work? A qualitative study of social class concealment and disclosure among white men employees who experienced upward mobility. Journal of Vocational Behavior, 113, 115128. https://doi.org/10.1016/j.jvb.2018.08.010

King, D. K. (1988). Multiple Jeopardy, Multiple Consciousness: The Context of a Black Feminist Ideology. Signs, 14(1), 42-72. http://www.jstor.org/stable/3174661

MacKinnon, C. A. (2013). Intersectionality as method: A note. Signs: Journal of Women in Culture and Society, 38(4), 1019-1030. https://doi.org/10.1086/669570

McCormick-Huhn, K., Warner, L. R., Settles, I. H., \& Shields, S. A. (2019). What if psychology took intersectionality seriously? Changing how psychologists think about participants. Psychology of Women Quarterly, 43(4), 445-456. https://doi.org/10.1177/0361684319866430

Mendez, D. D., Hogan, V. K., \& Culhane, J. F. (2014). Institutional racism, neighborhood factors, stress, and preterm birth. Ethnicity \& health, 19(5), 479-499. https://doi.org/10.1080/13557858.2013.846300

Mennies, R. J., Birk, S. L., Norris, L. A., \& Olino, T. M. (2020). The Main and Interactive Associations between Demographic Factors and Psychopathology and Treatment Utilization in Youth: A Test of Intersectionality in the ABCD Study 
Meyer, I. H. (2003). Prejudice, social stress, and mental health in lesbian, gay, and bisexual populations: Conceptual issues and research evidence. Psychological Bulletin; Washington, 129(5), 674-697. https://doi.org/10.1037/0033-2909.129.5.674

Rosenthal, L. (2016). Incorporating Intersectionality into psychology: An opportunity to promote social justice and equity. American Psychologist, 71, 474-485. https://doi.org/10.1037/a0040323

Settles, I. H. \& Buchanan, N. T. (2014). Multiple groups, multiple identities, \& intersectionality. In V. Benet-Martinez and Y. Hong (Eds.), The Oxford Handbook of Multicultural Identity (pp. 160-180). New York: Oxford University Press, Inc. http://doi.org/10.1093/oxfordhb/9780199796694.013.017

Settles, I. H., Warner, L., Buchanan, N. T., \& Jones, M. K. (2020). Understanding Psychology’s Resistance to Intersectionality Theory using a Framework of Invisibility and Epistemic Exclusion. Journal of Social Issues. Advance online publication. http://dx.doi.org/10.1111/josi.12403

Warner, L. R., Settles, I. H., \& Shields, S. A. (2016). Invited reflection: Intersectionality as an epistemological challenge to psychology. Psychology of Women Quarterly, 40(2), $171-$ 176. https://doi.org/10.1177/0361684316641384

Warnken, H., \& Lauritsen, J. (2019). Who Experiences Violent Victimization and Who Accesses Services? Findings from the National Crime Victimization Survey for Expanding Our Reach.

https://ncvc.dspacedirect.org/bitstream/item/1270/CVR\%20Article_Who\%20Experiences $\% 20$ Violent $\% 20$ Victimization $\% 20$ and $\% 20$ Who $\% 20$ Accesses $\% 20$ Services.pdf? sequence $=1$ 
Table 1: Core Tenets of Intersectionality Theory

Structures of oppression and inequality are mutually constitutive. Meaning that

Tenet 1 various "isms" (e.g., racism, sexism, classism, ableism, heterosexism) co-create and substantiate one another

Structures of oppression and inequality are interrelated and create matrices of power, privilege, and oppression that influence lived experiences and inform

Tenet 2 conceptualizations of social identities. As a result, understanding social group membership (e.g., sex, gender) requires in depth understanding of the other social identities one holds (e.g., race, class, sexual identity).

Theory and praxis must work in tandem and must focus on social justice. The Tenet 3 focus on social justice is comprehensive, influencing every phase of a given process, from planning, action, procedure, goals, and dissemination 